Revista aSEPHallus de Orientação Lacaniana

Núcleo Sephora de Pesquisa sobre o Moderno e o Contemporâneo

ISSN 1809 - $709 \mathrm{X}$

\title{
Memórias de um mau encontro com o Real: a pandemia de COVID 19
}

\author{
Tania coelho dos Santos \\ Orcid: https://orcid.org/0000-0002-5360-7864 \\ Pós-doutorado no Departamento de Psicanálise de Paris VIII (Paris, França) \\ Professor Associado, nível IV no Programa de Pós-graduação em Teoria Psicanalítica / UFRJ (Rio de Janeiro, \\ Brasil) \\ Pesquisadora do CNPQ nível 1 C Presidente do Instituto Sephora de Ensino e Pesquisa de Orientação \\ Lacaniana / ISEPOL (Rio de Janeiro, Brasil) \\ Psicanalista Membro da École de La Cause Freudienne (Brasil) \\ Membro da Escola Brasileira de Psicanálise e da Associação Mundial de Psicanálise (Paris, França) \\ Membro da Associação Universitária de Pesquisa em Psicopatologia Fundamental (Rio de Janeiro, Brasil) \\ E-mail: taniacs@openlink.com.br
}

A pandemia do novo Coronavírus desencadeou em todos os lugares do mundo uma estratégia feroz de combate epidemiológico que viria a modificar radicalmente a vida de todos. Isolamento social, higienização das mãos, alimentos, roupas e compras de supermercado ou farmácia são medidas que dolorosamente incorporaram-se à rotina. Hábitos distraídos como levar as mãos aos olhos, nariz e boca passaram a ser severamente proibidos. Nada disso se fez, portanto, sem um grande mal-estar. Passamos a nos assemelhar a indivíduos com sintomas obsessivos, o que não impediu que novas satisfações se revelassem e pequenas invenções restabelecessem a rede de relações sociais e de trabalho em novas bases. A vida é criativa e sempre triunfa sobre a destruição. Encontra sempre um jeito de recomeçar com novos custos.

A tecnologia alcançou um protagonismo inédito em nossas vidas. 0 e-commerce mostrouse à altura de substituir o comércio de rua e os adoráveis passeios pelos shoppings centers. Os Conselhos de Psicologia e Medicina autorizaram a prática dos atendimentos virtuais e as teleconsultas, que eram raras, tornaram-se a única forma de manter tratamentos de saúde não presenciais. Muitos psicanalistas rejeitaram aderir a essa prática. Outros, diferentemente, prosseguiram na sua rotina diária de atendimentos aos seus analisandos sem nenhuma ruptura. $\mathrm{E}$ uma boa parte aderiu com restrições e têm muitas críticas aos novos dispositivos clínicos à distância. Analisandos, igualmente, confessam não poder mais esperar o retorno aos atendimentos presenciais. Alguns preferiram, inclusive, interromper seus tratamentos. Uma grande parte aderiu e muitos declaram que não sentem diferença alguma. Exaltam as virtudes de uma modalidade de atendimento que Ihes permite aproveitar melhor o tempo em casa ou no trabalho, sem precisar dispender o tempo inútil de deslocamento pela cidade, submetidos a engarrafamentos 
estressantes. Como não poderia deixar de ser, esse novo número de aSEPHallus reúne artigos que testemunham as experiências desse evento que sacudiu a terra toda.

Trago em artigo intitulado Versões contraditórias no campo da ciência: politização e desinformação na prevenção à Covid-19 uma crítica do comportamento de alguns epidemiologistas e jornalistas. Para $80 \%$ dos infectados a Covid-19, nome da infecção que o novo coronavírus provoca, não passa de uma virose assintomática, com sintomas leves ou moderados. Porém, $5 \%$ dos indivíduos infectados desenvolvem sintomas muito graves, cujo tratamento é bastante complexo e pode levá-los a óbito. Difundiu-se na grande imprensa a ideia de que, no tratamento desta doença, o conhecimento médico-científico consolidado ao longo da experiência no tratamento de infecções respiratórias similares não serviria para nada. Desta forma, produziu-se entre os médicos assistentes uma enorme timidez ao explicar à imprensa que a utilização de métodos tradicionais de tratamento ainda era válida e não precisaria de complicados experimentos científicos para justificá-los. No público atingido pelas campanhas movidas pela imprensa observamos efeitos psicopatológicos de angústia intensa, insônia, falta de ar, fantasia de morte iminente e pânico.

Filipe Pereirinha, psicanalista português aborda em seu artigo o tema do estado de Emergência e tratamentos do real. Falar de emergência, ele nos explica, significa que houve algo inesperado e contingente que obrigou todo o mundo a responder à questão: e agora, o que fazer? Mas na resposta, isto é, no modo de tratar ou de lidar com isso que aconteceu, não há apenas um fazer, mas também um ou vários dizeres; daí que importe interrogar o que é este dizer, esta língua que usamos, é abusada ou nos abusa, conforme o caso, mas que por vezes implica igualmente uma certa torção que importa não perder de vista na prática analítica, pois é ela, porventura, a bússola que nos orienta.

Kátia Kac Nigri, pós-doutoranda no PPGTP, aborda A repercussão pública da guerra discursiva na pandemia da Covid-19. Seu trabalho apresenta os argumentos em defesa das orientações de prevenção e tratamento da doença do coronavírus. Ela analisa discursos contra e a favor do isolamento social, do uso da hidroxicloroquina e de tratamentos preventivos que se tornaram motivos de desavença e divisão na população. Tantos os médicos como muitas pessoas comuns tiveram que se posicionar em relação a esses discursos para conseguirem se orientar durante a pandemia. Muitos conflitos surgiram dessa divergência de pontos de vista. Ela aborda alguns deles e faz um levantamento a partir de um formulário piloto, respondido por vinte médicos, que trouxe uma indicação do quanto esses discursos os influenciaram ao decidirem o tratamento para seus pacientes com Covid-19.

Os professores do Núcleo de Pesquisa e Extensão em Psicanálise da UFSJ - Douglas Nunes Abreu, Fuad Kyrillos Neto, Maria Gláucia Pires Calzavara, Pedro Sobrino Laureano, Roberto Calazans e Wilson Camilo Chaves recordam a gripe espanhola e a comparam com a pandemia atual em seu artigo: Freud um século depois: trauma, pandemia e urgência subjetiva. Apresentam 
algumas contribuições teóricas da psicanálise neste momento em que o trauma assume um caráter mundial e cultural: a pandemia do novo coronavírus. Levando em consideração a questão do trauma, do inquietante, e das atuações em função da angústia em que a ameaça real da morte causa a todos, apresentam o dispositivo que adequaram para atuar com o auxílio da psicanálise sobre a urgência subjetiva. Por meio deste projeto de intervenção, o sujeito pode se apropriar de suas respostas a um trauma generalizado e elaborá-las.

Na Rede D'Or, a equipe constituída pela coordenadora Fernanda Saboya Almendra, a supervisora Tania Coelho dos Santos e as psicólogas Manuella Itapary Ribeiro Moreira e Maria Gabriela Severiano Ribeiro de Castro, traz sua experiência acerca da Psicanálise aplicada ao contexto hospitalar: intervenções em tempos de pandemia Covid-19 no artigo com este título. Essa prática é alicerçada nos princípios teórico-clínicos da psicanálise aplicada às práticas em instituições hospitalares. Há mais de uma década faz parte dos projetos de psicanálise aplicada do Instituto Sephora de Ensino e Pesquisa de Orientação Lacaniana. Essa experiência aqui relatada é inédita pois, pela primeira vez, foi necessário efetuar o acompanhamento psicanalítico virtualmente. A potência do dispositivo analítico, ancorado no campo da fala e da linguagem, precisou ser reinventada para alcançar pacientes com Covid-19 e seus familiares. Através de vinhetas clínicas são apresentadas algumas das dificuldades encontradas nesta nova prática em tempos de pandemia. Elas dão testemunho de zelo para que a ética e o desejo do analista as orientassem para fazer bom uso do novo dispositivo.

Juliana Bassoli Santos Soares e Patrícia Matos Rodrigues abordam A exigência psíquica dos rituais de despedida diante da morte em uma UTI da COVID-19 (Sars-CoV-2). Analisam em seu artigo o impacto da pandemia da COVID-19 no trabalho do psicólogo intensivista na Casa de Caridade de Muriaé Hospital São Paulo (CCMHSP). A assistência psicológica da CCMHSP orienta-se pelo viés da psicanálise aplicada ao contexto hospitalar. Em função do alto risco de contágio da Covid-19, as famílias estão impedidas de acompanhar de perto o processo da doença e da morte, dificultando a vivência do luto. Quais as consequências disso para os sujeitos?, elas se perguntam. As consequências psíquicas colocam-se para todos os envolvidos: profissionais de saúde, pacientes e familiares. As autoras analisam fragmentos das experiências hospitalares durante a epidemia da Covid-19 para refletir se os ritos de despedida são uma exigência psíquica diante do processo da morte e do luto de um ente querido. A construção teórica desse artigo acompanhou de perto a prática no hospital e suas manifestações diárias. O ofício da psicóloga intensivista as levou a afirmar que os rituais de despedida são uma necessidade psíquica para a elaboração do luto.

No Hospital Américas da Rede United Health Group, a coordenadora Mariana de Sá Freire Medrado Dias, a supervisora Tania Coelho dos Santos e as psicólogas Flavia Ribeiro Costa Pereira, Daniele Rangel dos Santos Rodrigues e Edineia Aparecida da Silva da Graça e Costa abordam com humor a experiência Quando o 'fique em casa' não era uma opção: os bastidores e os relatos das experiências dos profissionais de saúde no front de combate à pandemia da Covid-19 em seu 
artigo. Trata-se do estudo de um procedimento de extrema eficiência no combate à pandemia da Covid-19, a partir de uma análise das entrevistas realizadas com os profissionais de saúde que comandaram a linha de frente de um hospital particular da zona oeste do Rio de Janeiro. As entrevistas foram efetuadas com o objetivo de compreender a forma como esses profissionais enfrentaram a ameaça e responderam às demandas inauguradas durante a pandemia. Foi possível testemunhar a transformação da instituição desde a sua estrutura até a definição de protocolos de tratamento para uma doença naquele momento ainda desconhecida. Para a equipe de psicologia também foi preciso repensar o dispositivo clínico baseado na psicanálise aplicada e implementar novas intervenções, virtualmente, como resposta à crise.

Alinne Nogueira Silva Coppus perguntou a alguns colegas psicanalistas: Você vai voltar ao consultório? e nos trouxe as respostas que obteve acerca da "Psicanálise e atendimento on-line". Seu artigo interroga as possíveis consequências extraídas da realização dos atendimentos psicanalíticos na modalidade on-line como consequência da pandemia da Covid-19 que nos assolou em 2020. Problematizam-se os efeitos dessa experiência a partir de três eixos: a retomada de aspectos fundamentais da técnica psicanalítica, o conceito de transferência e a presença do analista bem como os significantes recolhidos de seus pares por meio de um questionário que os interrogou a prática dos atendimentos on-line.

Trazemos na seção Atualidades, o artigo da médica anestesista e especialista em clínica da dor, Mariana Gonçalves Musauer, sobre $A$ realidade não contada do enfrentamento à pandemia relatos de uma médica na linha de frente contra o novo coronavírus. Ela relata que no início da pandemia do novo coronavírus a classe médica foi tomada de incertezas que atrapalharam os uso do bom senso. Incerteza turbinadas pelas mídias sensacionalistas que anunciavam a catástrofe sem precedentes. O contexto criado pela mídia fez com que a maioria dos médicos se sentisse impotente diante da ameaça da "nova" doença. A desconstrução do saber médico se deu graças ás afirmações contundentes de epidemiologistas renomados lendo os números da epidemia pelos próprios números, distantes que ficaram da prática da assistência aos doentes. 0 bom senso médico não é construído em estudos randomizados e controlados, é construído com experiências. Em nossa prática, ela afirma, o cuidado é cem por cento das vezes individualizado.

Uma resenha muito oportuna nos foi encaminhada por Flavia Lana Garcia de Oliveira e Juliana Monteiro de Godoy acerca de: $O$ estatuto do corpo na psicanálise. Diante do acontecimento atual da pandemia, a dimensão do corpo parece emergir, primeiramente, em sua vulnerabilidade a um vírus que não pertence a nenhum viés ideológico, crença ou cultura, evocando nosso estado originário de profundo despreparo para aquilo que pode irromper na realidade sem pedir licença. Pensar o estatuto do corpo na psicanálise nos convida antes de tudo a um exercício minucioso de retorno à obra freudiana com a finalidade de demonstrar como essa noção foi articulada na teoria da clínica psicanalítica. Embora A Interpretação dos Sonhos (Traumdeutung) (Freud, 1900/2019) seja considerado o livro inaugural da psicanálise, já que nele a hipótese do inconsciente começa a 
ser estruturada, torna-se indispensável reconhecer que esse passo dado por Freud se fez a partir dos sintomas conversivos que impactam o corpo e o tornam palco de uma psicopatologia neurótica. $\mathrm{O}$ enigma do corpo histérico protagonizou o surgimento da psicanálise como método de diagnóstico e tratamento clínico.

Haja corpo! Em plena pandemia conseguimos colocar no ar dois números da nossa revista. Com que corpos isso foi feito? Com o dos autores a quem agradecemos imensamente pela sua contribuição. Mas também com os corpos generosos de Rosa Guedes Lopes, Flávia Lana G. de Oliveira, Catarina Coelho e Rebeca Espinosa Cruz Amaral que não deixaram que o clima soturno as impedisse de prosseguir. A esse corpo corajoso e forte, meu muito obrigada!

Citação/Citation: Coelho dos Santos, T. (nov. 2019 a abr. 2020). Memórias de um mau encontro com o Real: a pandemia de COVID 19. Revista aSEPHallus de Orientação Lacaniana, 15(29), 1-5. Disponível em www.isepol.com/asephallus. Doi: 10.17852/1809-709x.2020v15n29p01-05

Editor do artigo: Tania Coelho dos Santos.

Recebido/Received: 10/03/2019 / 03/10/2019.

Aceito/Accepted: 10/20/2019 / 20/10/2019.

Copyright: ( 2019 Associação Núcleo Sephora de Pesquisa sobre o moderno e o contemporâneo. Este é um artigo de livre acesso, que permite uso irrestrito, distribuição e reprodução em qualquer meio, desde que $o$ autor $e$ a fonte sejam citados/This is an open-access article, which permites unrestricted use, distribution, and reproduction in any medium, provided the author and source are credited. 